\title{
Application of Artificial Intelligence in Innovation Experiment Management System Engineering
}

\author{
Wei Gao ${ }^{1,2, a}$,Qiang Qi ${ }^{1,2, b}$,Lan Dong ${ }^{1,2, c}$ and Cui Liu 1,2,d* \\ ${ }^{1}$ School of Mechanical and Electrical Engineering, Qingdao Binhai University, Qingdao, Shandong, \\ PR China, 266555 \\ ${ }^{2}$ Engineering and Technology R\&D center of Mechanical and Electrical in Colleges of Shandong, \\ Qingdao Binhai University, Qingdao, Shandong, PR China, 266555 \\ a1533150757@qq.com,b66851766@qq.com, ${ }^{\mathrm{c} 804203464 @ q q . c o m,{ }^{\mathrm{d}} 187184286 @ q q . c o m}$
}

Keywords: Neural network; Innovative product quality assessment; Innovation and entrepreneurship; Experimental teaching

\begin{abstract}
Artificial intelligence is a cross-cutting and marginal discipline involving computer science, cybernetics, informatics, psychology, philosophy, and decision-making. This paper tries to use the combination of artificial intelligence and system engineering to propose artificial intelligence planning and decision-making problems of innovative products in experiments. As an indispensable part of the control and decision-making system, artificial intelligence decision-making is dominated by computer planning. Combining the empirical coefficient with the research direction setting and planning, intelligently detecting the problem and realizing intelligent decision-making.
\end{abstract}

\section{Introduction}

With the development of science and technology, today's society puts forward higher requirements for the knowledge, ability and skills of talents. Higher education emphasizes on cultivating students' comprehensive literacy and practical ability. How to improve the quality of experimental teaching, strengthen the cultivation of students' practical ability and innovative ability, how to further deepen the reform of experimental teaching, and cultivate high-quality innovative talents that can meet the needs of economic and social development, and become the subject of research and attention of all schools. Combined with the system engineering of laboratory management, the application of artificial intelligence in the management system is proposed. The artificial intelligence management system was discussed, the effective application rate of experimental scientific research products and the new product listing rate were improved, the role of scientific research personnel's innovation ability training was evaluated, the research status of existing innovative product practice application was analyzed, and further innovation evaluation system was proposed.

\section{Innovation and Entrepreneurship Education}

In recent years, innovation and entrepreneurship education has become the core content of the strategic transformation and mission reshaping of higher education institutions in the world. It has also become a symbol of the concept of disseminating innovative entrepreneurship, knowledge and skills, and creating social wealth. Duwell-Cuertier and Dean Foss pointed out that in engineering education, entrepreneurship education is often considered part of innovative education and is closely integrated with innovative education that focuses on creativity, product design and development, new technologies or new product management. Udine and Hill believe that innovation is the process of transforming imagination or creative ideas and design into practical applications. Entrepreneurship is the process of commercializing or marketing innovation, and innovation can stimulate entrepreneurial will and behavior, which is the foundation of entrepreneurship. At the same time, they believe that imagination, creativity and design thinking are closely related to innovation. They are the key content of innovation and entrepreneurship education. Therefore, a 
new engineering course integrating imagination, creativity and design thinking training has been designed to improve the innovation and entrepreneurship of engineering students.

Innovative entrepreneurship education has long been recognized as one of the key factors in cultivating and strengthening students' attitudes toward innovation and entrepreneurship. Researchers and practitioners also generally believe that thinking patterns, attitudes, skills and knowledge, and other personal traits associated with innovative entrepreneurship can be effectively nurtured and developed through innovation and entrepreneurship education. For example, Colin and Jack pointed out that innovation and entrepreneurship education is a process that can strengthen students' business opportunity insight and recognition ability, as well as a process to develop students' innovative entrepreneurial thinking patterns, attitudes, knowledge and skills. Liem believes that innovation and entrepreneurship education can help enhance personal security, belonging, self-efficacy, autonomy, identity and sense of accomplishment. At the same time, it also helps to develop individual innovation and entrepreneurial thinking and its innovative entrepreneurial confidence and knowledge and skills, to develop students' innovative entrepreneurial thinking, attitudes, skills and knowledge, to become the talents needed for the national innovation-driven development strategy.

\section{The Status Quo and Problems of Experimental Teaching}

1. The traditional experimental teaching is mainly based on the teacher's explanation and demonstration. The teacher explains the purpose of the experiment, the instruments used, the experimental principle and the specific operation process. The students only need to complete the experiment according to the experimental steps and methods within the prescribed experimental time. This experimental mode passively conducts experiments and operations, is limited to basic experimental operation skills training and consolidates the knowledge acquired, and is not conducive to cultivating students' practical ability and innovative spirit.

2. The number of enrolled students in higher education institutions has increased, and the conditions for running schools are limited. The application-based undergraduate school laboratories cannot guarantee that each student can operate the experimental equipment during the planned experimental time, resulting in poor experimental teaching results. Therefore, after the end of the experimental teaching, the experimental results can't be analyzed in depth, and there are not many students who have deepened their understanding and mastery of theoretical knowledge through experiments, and cannot achieve the intended purpose of experimental teaching.

3. Due to financial constraints, laboratory equipment and equipment updates can't keep up with the development of new products and new technologies, and advanced experimental techniques and methods cannot be applied in time. Traditional experimental teaching content often lags behind the emergence and development of new technologies. At present, many ordinary colleges and universities face similar problems.

\section{Experimental Project Open Safeguard Measures}

1. Strengthen the management of open laboratories, formulate and improve rules and regulations Open experimental management is more complex than traditional experimental management. First of all, it is necessary to improve the laboratory management system and formulate open rules and regulations for experimental projects to ensure the smooth opening of experimental projects. Secondly, students should be familiar with the laboratory management system and strictly enforce the management regulations before conducting open experiments. For example, some valuable instruments and equipment must be trained by professional technicians; some special instruments and equipment must be used after mastering the use of the instrument to maximize the safety of the equipment and ensure the smooth progress of the experiment. .

2. Using virtual experiment system to realize the opening of teaching methods

The purpose of open-type experimental teaching is to cultivate students' innovative ability and practical ability. Therefore, traditional teaching methods have lagged behind, and experimental 
teaching methods are open to meet the needs of open-ended experiments. With the development of computer technology, virtual technology has been widely used in experimental teaching. For example, in the vehicle engineering laboratory automatic transmission disassembly and opening experiment project, students can use the automatic transmission virtual disassembly software to simulate disassembly and assembly, and repeatedly operate the automatic transmission disassembly technology, and then physically disassemble, so as to avoid damage to the real automatic transmission. It can also break through the limitations of automatic transmission types and improve the utilization of laboratory resources.

3. Strengthen the construction of experimental teachers and increase the investment in laboratory openness

The research and innovative experimental content reflects the development level of modern science and technology and involves a wide range of knowledge. All of these require experimental teachers and experimental technicians not only to have certain scientific research capabilities and experimental skills, but also to strengthen professional learning, and constantly broaden the knowledge to meet the opening requirements of experimental projects. The school also needs to provide experimental personnel with advanced learning and daily professional learning opportunities to improve their research and innovation capabilities. In addition, as the use of laboratory open instruments and equipment increases, equipment maintenance and maintenance costs increase, and various consumables will increase accordingly, which requires an increase in laboratory funding.

4. Strengthening laboratory open work with open experimental network management system

In order to ensure the normal operation of the open experiment, an experimental network information management platform can be established. Using the experimental teaching network management system, students are free to choose experimental projects and experimental time, conduct experimental learning and communication online, and use the networked experimental system to complete experiments outside the laboratory. At the same time, teachers can make full use of the experimental teaching network management system, understand the latest experimental teaching arrangements, timely grasp the student's experimental completion, and also conduct online Q\&A(Question and Answer) and remote operation guidance to improve the efficiency of experimental teaching management.

5. Strengthening the quality monitoring of open experimental projects is the quality assurance of experimental projects

At the middle and end of the semester, the school organizes special personnel to check the opening of the laboratory during the semester. The teaching supervisor inspects the teaching materials of the open experimental project completed in the previous semester, holds a student symposium, understands the implementation of the open experimental project, evaluates the effectiveness of the open experimental teaching, and raises questions and suggestions. The Academic Affairs Office regularly organizes laboratory open work summary meetings, and conducts discussions with experimental instructors to sum up experience, improve deficiencies, and promote the improvement of laboratory open teaching quality.

\section{Application of Neural Network in Innovation Experiment Evaluation Index System}

The objectives of the quality evaluation index system and quality evaluation are to promote the construction of innovation laboratories in a certain direction. The evaluation indicators are decomposed according to the evaluation objectives. It is of great significance to evaluate the quality of innovation laboratory construction. Only the evaluation conducted on the scientific and correct evaluation index system can give play to the orientation, identification and incentive role of innovation evaluation. From the overall perspective of current innovation experiments, the following indicators are identified.

1. First-level indicators. The utilization rate of experimental equipment, namely: (1)setting of innovative procedures; (2) related application technologies; (3) market research results of 
experimental innovative products; (4) research utilization rate of research and development personnel.

2. Secondary indicators. Experimental content, namely: (1)correctness; (2)advanced; (3)theory linked to practice; (4)practical effects; (5)relevant practical level.

3. Evaluation of innovative products. Namely: (1)novelty of experiment; (2)ability to develop new product; (3new product comparison; (4)product plan establishment; (5)program in the process of revision; 6In the process of innovation and invention, the practicality and correctness of the applied disciplines.

4. Social demand. Namely: (1)the practicality of innovative products; (2)the novelty of invention; (3)the adoption rate and output value of independent innovation products in the market; (4)the value of innovation to society; (5)the quantification of scientific research results; 6)transformation rate of scientific research results

\section{Problems and Solutions to the Quality Evaluation Index System}

The innovation quality evaluation index system has different emphasis on different objectives and different periods, but it is relatively stable in a certain period. The weight of each indicator in the indicator system should reflect the innovative concept of a project in a certain period of time, which is the specific requirement for the innovation effect of each project. In the quality evaluation of the project, since the evaluation of the evaluated person depends on the comprehensive needs of the evaluator's experience, knowledge, investigation and judgment, and market demand, this evaluation is a nonlinear problem, and the nerve of quality evaluation network mathematical model is proposed according to this feature.

The learning data of the particle swarm neural network model is derived from the scores of the authoritative experts on the project. The input data is the score of the evaluation index, and the output data is the evaluation result of the evaluator. Through the training of the network model, the evaluation results of the indicators according to different evaluation directions can be obtained, and the evaluation results of the project quality can be obtained, and the market demand judgment, the knowledge, the experience of the authoritative experts, and the understanding of the importance of the indicators can be reproduced. Find out the most feasible solution. It is also possible to evaluate ongoing projects to correct the direction of the project's later development.

\section{Application of Neural Network in Laboratory Quality Assessment}

1. Innovative quality assessment method

In order to demonstrate the composition of the project evaluation index system scientifically, comprehensively, objectively and clearly, it is divided into three levels: (1)Basic knowledge element layer. Its function is the basic knowledge. (2) Market evaluation factor layer. On the basis of the basic elements, the variables of the surface tension state are extracted, and the internal and external variables are used to reflect the composition of the evaluation factors. (3)Indicator layer. Further refine the state of various evaluation factors, and more intuitively and concretely reflect the explicit features of core competitiveness in this element. Through systematic analysis and rational integration of factors affecting competitiveness, six basic elements (basic knowledge, existing knowledge demand structure, key problem solving, market acceptance, cooperation ability among researchers) and experimental resources are constructed. A three-level core competitiveness evaluation index system consisting of 17 evaluation factors such as comprehensive utilization of experimental resources and social evaluation of innovation value and 70 evaluation indicators are also constructed.

2. Implementation of particle swarm neural network and operation results

The equal particle swarm neural network model is realized by Matlab. These include: market operation ratings, user ratings, corporate ratings, scientific and technical personnel ratings, 
high-tech expert ratings, patent conversion rate ratings, and assessment scores by leading experts.

3. Determination of the number of neurons in the input layer

The project is a multidisciplinary collaboration and crossover. It emphasizes the transformation and application of originality and results. The general innovative products are cross-disciplinary, emphasizing the coordination of various disciplines, team members can complement each other, team leaders have market strategic vision and strong coordination organization.

\section{Summary}

The neural network particle swarm model is applied to the quality assessment. Through the system learning, an appropriate weight is determined. The score with high credibility is higher, and the score with lower credibility is lower. In this way, the scores of various groups can be input to obtain a more objective quality assessment score.

\section{Acknowledgements}

This work is supported by the National Natural Science foundation of hina(51806112),Development Project of Shandong Higher Education Institutions,China(J16LN92,J17KB016,J18KA017),Key technology project of Qingdao Binhai University(2017KZ013).

\section{References}

[1]Chen D. Supporting Uncertainty in Standard Database Management Systems[J]. Information Sciences, 2012, 184(1):196-214.

[2]Abanda F H, Tah J H M, Keivani R. Trends in built environment semantic Web applications: Where are we today?[J]. Expert Systems with Applications, 2013, 40(14):5563-5577.

[3]Mahajan A S, Pattar R Y, Khamitkar R, et al. Doctor's innovative clinic: An application of artificial intelligence and physiological sensors[C]// International Conference on Advances in Human Machine Interaction. IEEE, 2016:1-5.

[4]Ko C H. Integrating RFID, web-based technology, and artificial intelligence in engineering management[J]. Scientia Iranica, 2015, 22(2):299-312.

[5]Yang X D, Hao X M. An Application of Artificial Intelligence Electric Management System in University Apartment Fire-proof Subject[J]. Journal of Shandong Agricultural University, 2015.

[6]Zahraee S M, Assadi M K, Saidur R. Application of Artificial Intelligence Methods for Hybrid Energy System Optimization[J]. Renewable \& Sustainable Energy Reviews, 2016, 66:617-630.

[7]Strohmeier S, Piazza F. Artificial Intelligence Techniques in Human Resource Management-A Conceptual Exploration[J]. Intelligent Systems Reference Library, 2015, 87:149-172.

[8]Sica F C, Guimarães F G, Duarte R D O, et al. A cognitive system for fault prognosis in power transformers[J]. Electric Power Systems Research, 2015, 127:109-117.

[9]Z. Li, J. Wang. An optimization application of artificial intelligence technology in enterprise financial management[J]. Boletin Tecnico/technical Bulletin, 2017, 55(11):83-89.

[10]Yu M, Feng X, Zhu Z. The Educational Applications and Innovative Explorations of Machine Learning in the View of Artificial Intelligence[J]. Journal of Distance Education, 2017.

[11]Kouziokas G N. Decision Support System Based on Indicators and Artificial Intelligence in Public and Environmental Management $[\mathrm{C}] / /$ International Conference on Environmental Management, Engineering, Planning and Economics. 2017.

[12]Song J U, Yang X D. Research and Application of Artificial Intelligence Technology in Construction Industry at Home and Abroad[J]. Value Engineering, 2018.

[13]Zhang X M, Zi-Wu Y U, Yang Y Q. Application and Consideration to Boeing 787 Influenced by Artificial Intelligence[J]. Industrial Engineering \& Management, 2017.

[14]Kuo P H, Huang C J. A Green Energy Application in Energy Management Systems by an Artificial Intelligence-Based Solar Radiation Forecasting Model[J]. Energies, 2018, 11(4):819. 